\title{
Seasonal variability in clinical care of COPD outpatients: results from the Andalusian COPD audit
}

\begin{abstract}
Jose Luis López-Campos, 1,2 Maria Abad Arranz,' Carmen Calero-Acuña, ${ }^{1,2}$ Fernando Romero-Valero, ${ }^{3}$ Ruth Ayerbe-García, ${ }^{4}$ Antonio Hidalgo-Molina, ${ }^{3}$ Ricardo I Aguilar-Pérez-Grovas, ${ }^{4}$ Francisco García-Gil, ${ }^{5}$ Francisco Casas-Maldonado, ${ }^{6}$ Laura Caballero-Ballesteros, ${ }^{5}$ María Sánchez-Palop, ${ }^{6}$ Dolores Pérez-Tejero, ${ }^{7}$ Alejandro Segado Soriano,' Jose Calvo-Bonachera, ${ }^{8}$ Bárbara Hernández-Sierra, ${ }^{8}$ Adolfo Doménech, ${ }^{9}$ Macarena ArroyoVarela, ${ }^{9}$ Francisco GonzálezVargas, ${ }^{10}$ Juan J Cruz-Rueda ${ }^{10}$

'Unidad Médico-Quirúrgica de Enfermedades Respiratorias, Instituto de Biomedicina de Sevilla (IBiS), Hospital Universitario Virgen del Rocío/Universidad de Sevilla, Seville, ${ }^{2}$ CIBER de Enfermedades Respiratorias (CIBERES), Instituto de Salud Carlos III, Madrid, ${ }^{3}$ Sección de Neumología, Hospital Puerta del Mar, Cádiz, ${ }^{4}$ Servicio de Neumología, Hospital Juan Ramón Jiménez, Huelva, ${ }^{5}$ Servicio de Neumología, Hospital Universitario Reina Sofía, Córdoba, 'Servicio de Neumología, Hospital Universitario San Cecilio, Granada, ${ }^{7}$ Sección de Neumología, Hospital Infanta Margarita, Cabra, Córdoba, ${ }^{8}$ Servicio de Neumología, Hospital Torrecárdenas, Almería, 'Servicio de Neumología, Hospital Regional Universitario de Málaga, Málaga, ${ }^{10}$ Servicio de Neumología, Hospital Universitario Virgen de las Nieves, Granada, Spain
\end{abstract}

Correspondence: Jose Luis López-Campos Unidad Médico-Quirúrgica de Enfermedades Respiratorias, Instituto de Biomedicina de Sevilla (IBiS), Hospital Universitario Virgen del Rocio Avda. Manuel Siurot, s/n 41013 Seville, Spain Tel +349550I 3166

Email lopezcampos@separ.es
This article was published in the following Dove Press journal:

International Journal of COPD

3 March 2017

Number of times this article has been viewed

Objectives: Clinical practice in chronic obstructive pulmonary disease (COPD) can be influenced by weather variability throughout the year. To explore the hypothesis of seasonal variability in clinical practice, the present study analyzes the results of the 2013-2014 Andalusian COPD audit with regard to changes in clinical practice according to the different seasons.

Methods: The Andalusian COPD audit was a pilot clinical project conducted from October 2013 to September 2014 in outpatient respiratory clinics of hospitals in Andalusia, Spain ( 8 provinces with more than 8 million inhabitants) with retrospective data gathering. For the present analysis, astronomical seasons in the Northern Hemisphere were used as reference. Bivariate associations between the different COPD guidelines and the clinical practice changes over the seasons were explored by using binomial multivariate logistic regression analysis with age, sex, Charlson comorbidity index, type of hospital, and COPD severity by forced expiratory volume in 1 second as covariates, and were expressed as odds ratio (OR) with $95 \%$ confidence intervals (CIs).

Results: The Andalusian COPD audit included 621 clinical records from 9 hospitals. After adjusting for covariates, only inhaler device satisfaction evaluation was found to significantly differ according to the seasons with an increase in winter (OR, 3.460; 95\% CI, 1.469-8.151), spring (OR, 4.215; 95\% CI, 1.814-9.793), and summer (OR, 3.371; 95\% CI, 1.391-8.169) compared to that in autumn. The rest of the observed differences were not significant after adjusting for covariates. However, compliance with evaluating inhaler satisfaction was low.

Conclusion: The various aspects of clinical practice for COPD care were found to be quite homogeneous throughout the year for the variables evaluated. Inhaler satisfaction evaluation, however, presented some significant variation during the year. Inhaler device satisfaction should be evaluated during all clinical visits throughout the year for improved COPD management.

Keywords: COPD, seasons, clinical practice, quality of care

\section{Introduction}

Chronic obstructive pulmonary disease (COPD) is a respiratory condition with clinical manifestations that affect not only the quality of life and prognosis but also the overall health of the patient. ${ }^{1}$ Consequently, care of COPD patients should comply with the clinical guidelines to ensure optimal clinical care. ${ }^{2}$ In this context, clinical audits have emerged as a tool to measure clinical activity and benchmark it against known clinical standards. ${ }^{3}$ Previous clinical audits in COPD care have shown variability in clinical practices across hospitals and countries after adjusting for different confounders. ${ }^{4}$

Interestingly, weather changes considerably affect chronic respiratory diseases. ${ }^{5}$ Various respiratory conditions, including asthma ${ }^{6}$ and cystic fibrosis, ${ }^{7}$ are known to 
exacerbate during winter. In COPD, especially, the number of exacerbations rises during winter months, ${ }^{8}$ with an increase in the number of admissions and readmissions, ${ }^{9}$ and the corresponding implications on treatment selection. ${ }^{10}$ Additionally, respiratory virus infection is more common in the winter and virus-associated exacerbations take longer to recover from. ${ }^{11}$

Consequently, clinical practice in COPD care can be influenced by weather variability throughout the year. Unfortunately, the effect of different seasons on clinical practice in COPD care has not been evaluated thus far, and previous clinical audits have not taken into account the climatic changes and their potential effect on clinical care. In Spain, the weather varies from very high temperatures and high pressures during the summer to considerably cold winter months with temperatures reaching $<0^{\circ}$ in some areas, warranting an investigation on the influence of climatic changes on clinical care for COPD.

During the period 2013-2014, a clinical audit was conducted on COPD outpatients of hospitals in Andalusia, Spain (more than 8 million inhabitants). ${ }^{12}$ The present study analyzes the results of this Andalusian COPD audit with regard to potential seasonal changes in clinical practice, in order to explore the hypothesis of seasonal variability in COPD clinical care throughout the year.

\section{Methods}

The Andalusian COPD audit was a pilot clinical audit conducted from October 2013 to September 2014 in outpatient respiratory clinics of hospitals in Andalusia, Spain (8 provinces with more than 8 million inhabitants). The methodology used has been extensively reported previously. ${ }^{12}$ In brief, $20 \%$ of the centers in the area were invited to participate in this audit. The selection of centers was based on participation in previous audits and was voluntary. As it was a pilot study, randomization was not performed, and therefore, we did not aim to achieve representative sampling.

Patients with an established COPD diagnosis based on risk factors, clinical symptoms, and a post-bronchodilator forced expiratory volume in 1 second/forced vital capacity $\left(\mathrm{FEV}_{1} /\right.$ FVC) ratio $<0.70$ were deemed to be eligible. ${ }^{13}$ As our goal was to assess the usefulness of formally scheduled regular follow-up visits, only cases with at least 1 year of follow-up were included in the audit. Patients who underwent their first diagnostic visit or presented with an exacerbation were not eligible. Similarly, subjects with significant respiratory comorbidities that could influence COPD treatment approach were excluded according to the local investigator's discretion.
Based on our previous experience, we estimated that 80 cases per center would be required for this pilot study. Recruitment for the 1-year audit was performed in 4 quarters (October-December 2013, January-March 2014, AprilJune 2014, and July-September 2014). At the beginning of each trimester, investigators were instructed to identify consecutive COPD cases until the desired sample size of 20 per trimester was reached.

The clinical practice of outpatient clinics was benchmarked against the clinical guidelines available at the time of the audit. During the study period, the GOLD $2013^{13}$ and the Spanish National Guideline for COPD (GesEPOC) ${ }^{14}$ were widely and uniformly used in Spain. We, therefore, carefully reviewed these 2 guidelines to extract relevant clinical recommendations for benchmarking the clinical practices audited. We also considered the guidelines of the 2009 Spain HealthCare Quality Standards in COPD, which were applicable at the time of the audit. ${ }^{15}$ The final database included 55 variables for the resources and 182 variables for the clinical database. Among the items evaluated, it was verified whether doctors assessed the patient satisfaction with the inhaler. For this purpose, investigators were asked whether the degree of satisfaction with the inhalation device was recorded during the clinical visit with 2 possible answers: yes or no.

For the present analysis, astronomical seasons in the Northern hemisphere were used as reference. Thus, December 21 to March 20 was considered winter, March 21 to June 20 was spring, June 21 to September 20 was summer, and September 21 to December 20 was autumn.

The audit was approved by the Ethics Committee of the Hospital Universitario Virgen del Rocío (code: 2013PI/201). Clinical records were anonymized in the database by assigning a numerical code through an algorithm. No personal information that could be used directly or indirectly to identify an individual was registered. The relationship between the audit code and the clinical history number was kept local and was the local investigator's responsibility. Because of the retrospective nature of the study, the anonymization of data, and the lack of active diagnostic or therapeutic interventions, informed consents were not required according to the Ethics Committee of the Hospital Universitario Virgen del Rocío.

\section{Statistical analyses}

All computations were performed using the Statistical Package for Social Sciences, version 23.0 (SPSS; IBM Corporation, Armonk, NY, USA). Before performing any analysis, the database was evaluated for quality. The values that were extreme from a clinical point of view, missing, or 
inconsistent were returned to the investigators for correction. Clinical variables are presented as the mean and standard deviations or absolute and relative frequencies, as appropriate for displaying the results of the entire cohort and dividing them by seasons. The variability was expressed by using the interhospital range, which represents the highest and lowest mean value from the participant centers. The significance of this variability was explored using the Chi-square test or analysis of variance (ANOVA) between the different participant centers. Crude differences between seasons were evaluated using ANOVA or the Chi-square test, depending on the nature of the variable. We then explored the relationship between the doctor's adherence to the different guideline recommendations and season-related changes by performing a binomial multivariate logistic regression analysis using the enter method adjusted for age, sex, Charlson comorbidity index, type of hospital, and COPD severity by $\mathrm{FEV}_{1}$. The results were expressed as odds ratio (OR) with 95\% confidence intervals (CIs). The alpha error was set at 0.05 .

\section{Results}

Overall, 621 clinical records from 9 hospitals were audited. The patient characteristics of the audited cases are summarized in Table 1. Most patients were men in the seventh decade of life, and a considerable proportion of patients were current smokers; in addition, homogeneous distribution of comorbidities and moderate-to-severe lung function impairment were noted.

The distribution of the information obtained during the clinical interview over the 4 seasons is presented in Table 2. The occurrence of dyspnea recorded using the modified Medical Research Council (mMRC) scale and the COPD

Table I Patient characteristics

\begin{tabular}{|c|c|c|c|}
\hline Variables & Average* & Interhospital range & $P$-value $\#$ \\
\hline Age (years) & $68.3(9.8)$ & $64.7-69.7$ & 0.100 \\
\hline Male sex (n) & $527(84.9)$ & $51.7-94.8$ & $<0.001$ \\
\hline Current smokers (n) & $163(26.2)$ & $18.5-40.0$ & $<0.001$ \\
\hline Tobacco history (pack-years) & $54.7(30.5)$ & $42.5-66.6$ & $<0.001$ \\
\hline Comorbidities (Charlson) & $2.15(1.5)$ & I.8-2.4 & 0.577 \\
\hline Psychiatric comorbidities (n) & $126(20.3)$ & $12.3-24.1$ & 0.779 \\
\hline Cardiovascular comorbidities (n) & $163(26.2)$ & |8.2-37.5 & 0.072 \\
\hline Previous neoplasms (n) & $92(14.8)$ & $8.6-21.0$ & 0.532 \\
\hline Time from diagnosis (years) & $5.5(5.9)$ & $1.06-6.9$ & 0.033 \\
\hline \multicolumn{4}{|l|}{ GesEPOC phenotype } \\
\hline Nonfrequent exacerbator $(n)$ & $297(47.8)$ & $0-85.2$ & $<0.001$ \\
\hline Mixed (n) & $64(10.3)$ & $3.7-22.5$ & $<0.001$ \\
\hline Frequent exacerbator with emphysema (n) & $50(8.1)$ & $0-17.3$ & $<0.00$ I \\
\hline Frequent exacerbator with chronic bronchitis ( $n$ ) & $90(14.5)$ & $0-34.2$ & $<0.001$ \\
\hline Not available (n) & $120(19.3)$ & 0-88.9 & $<0.001$ \\
\hline \multicolumn{4}{|l|}{ GOLD types } \\
\hline Type A (n) & $115(18.5)$ & $0-40.7$ & $<0.001$ \\
\hline Type B (n) & $60(9.7)$ & $0-21.9$ & $<0.001$ \\
\hline Type C (n) & $100(16.1)$ & $0-38.3$ & $<0.001$ \\
\hline Type D (n) & $109(17.6)$ & $0-32.9$ & $<0.001$ \\
\hline Not available (n) & $237(38.2)$ & $0-100$ & $<0001$ \\
\hline Previous hospitalizations (n) & $0.9(1.6)$ & $0.1-1.3$ & $<0.001$ \\
\hline$\alpha I$-Antitrypsin determined (n) & $164(26.4)$ & $2.5-53.2$ & $<0.001$ \\
\hline Some sputum microbiology in the past (n) & $264(42.5)$ & II.3-64.2 & $<0.001$ \\
\hline Some sputum isolation in the past $(n)$ & $23(3.7)$ & $0-11.1$ & $<0.001$ \\
\hline BODE available (n) & $60(9.7)$ & $0-32.5$ & $<0.001$ \\
\hline BODEx available (n) & $145(23.3)$ & $0-96.3$ & $<0.001$ \\
\hline Body mass index $\left(\mathrm{kg} / \mathrm{m}^{2}\right)$ & $28.2(5.3)$ & $26.0-29.6$ & 0.009 \\
\hline FVC (\%) & $74.6(20.7)$ & 63.7-98.4 & $<0.001$ \\
\hline $\mathrm{FEV}_{1}(\%)$ & $51.9(19.7)$ & $42.7-59.1$ & 0.001 \\
\hline Monographic clinic (n) & $229(36.9)$ & $0-100$ & $<0.001$ \\
\hline Clinic located in the hospital (n) & $607(97.7)$ & $82.7-100$ & $<0.001$ \\
\hline
\end{tabular}

Notes: *Data are expressed as mean (SD) or absolute (relative) frequencies depending on the nature of the variable. ${ }^{\#}$ Calculated for the variability between centers using ANOVA and Chi-square test, depending on the nature of the variable.

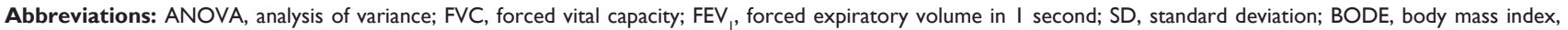
obstruction, dyspnea, and excercise. 
Table 2 Data recorded in the clinical interview

\begin{tabular}{|c|c|c|c|c|c|c|c|c|}
\hline Variables & $\begin{array}{l}\text { Average* } \\
(n=62 I)\end{array}$ & $\begin{array}{l}\text { Interhospital } \\
\text { range }\end{array}$ & $P$-value $\#$ & $\begin{array}{l}\text { Autumn } \\
(\mathrm{n}=179)\end{array}$ & $\begin{array}{l}\text { Winter } \\
(n=144)\end{array}$ & $\begin{array}{l}\text { Spring } \\
(\mathrm{n}=175)\end{array}$ & $\begin{array}{l}\text { Summer } \\
(n=123)\end{array}$ & $P$-value ${ }^{\ddagger}$ \\
\hline \multicolumn{9}{|l|}{ Anamnesis } \\
\hline Dyspnea recorded $(n)$ & $560(90.2)$ & $80.8-100$ & $<0.001$ & $154(86.0)^{\S}$ & $136(94.4)$ & $158(90.3)$ & II2 (9I.I) & 0.088 \\
\hline Dyspnea recorded by mMRC scale (n) & $489(78.7)$ & $39.7-100$ & $<0.00$ I & $137(76.5)$ & $125(86.8)^{\S}$ & I 38 (78.9) & $89(72.4)$ & 0.028 \\
\hline CAT questionnaire registered $(n)$ & $108(17.4)$ & $0-93.8$ & $<0.00$ I & $29(16.2)$ & $28(19.4)$ & $30(17.1)$ & $2 I(17.1)$ & 0.893 \\
\hline $\begin{array}{l}\text { Clinical situation evaluated by mMRC } \\
\text { or CAT }\end{array}$ & $489(78.7)$ & $39.7-100$ & $<0.001$ & 137 (76.5) & $125(86.8)^{\S}$ & $138(78.9)$ & $89(72.4)$ & 0.028 \\
\hline Cough and sputum registered $(\mathrm{n})$ & $551(88.7)$ & $62.5-100$ & $<0.001$ & $155(86.6)$ & $|3|(9 \mid .0)$ & $154(88.0)$ & III (90.2) & 0.590 \\
\hline Sputum color recorded $(n)$ & $499(80.4)$ & $35.0-100$ & $<0.00$ I & $135(75.4)^{\S}$ & $12 \mid(84.0)$ & I 36 (77.7) & $107(87.0)^{\S}$ & 0.042 \\
\hline Asthma-like symptoms recorded (n) & $544(87.6)$ & $50.0-100$ & $<0.001$ & $155(86.6)$ & $130(90.3)$ & $152(86.9)$ & $107(87.0)$ & 0.741 \\
\hline Previous exacerbations recorded (n) & $556(89.5)$ & $57.5-98.7$ & $<0.001$ & I5I $(84.4)^{\S}$ & $129(89.6)$ & $160(9 \mid .4)$ & I I 6 (94.3) & 0.032 \\
\hline Hospitalizations recorded (n) & $588(94.7)$ & $55.0-100$ & $<0.001$ & $161(89.9)^{\S}$ & I $37(95.1)$ & $168(96.0)$ & $122(99.2)^{\S}$ & 0.003 \\
\hline \multicolumn{9}{|l|}{ Current treatments } \\
\hline Smoking status recorded (n) & $591(95.2)$ & $72.4-100$ & $<0.001$ & $164(91.6)^{\S}$ & I $37(95.1)$ & $169(96.6)$ & $12 \mid(98.4)$ & 0.038 \\
\hline Exercise recorded $(n)$ & $403(64.9)$ & $24.7-100$ & $<0.00$ I & $109(60.9)$ & $104(72.2)^{\S}$ & $114(65.1)$ & $76(61.8)$ & 0.159 \\
\hline Influenza vaccination recorded $(\mathrm{n})$ & $34 \mid(54.9)$ & $16.0-93.8$ & $<0.001$ & $92(51.4)$ & $83(57.6)$ & $100(57.1)$ & $66(53.7)$ & 0.625 \\
\hline Pneumococcal vaccination recorded $(n)$ & $231(37.2)$ & $5.0-95.1$ & $<0.001$ & $63(35.2)$ & $61(42.4)$ & $57(32.6)$ & $50(40.7)$ & 0.243 \\
\hline $\begin{array}{l}\text { Current pharmacological treatment } \\
\text { recorded }(n)\end{array}$ & $568(91.5)$ & $53.8-100$ & $<0.001$ & $170(95.0)^{\S}$ & $136(94.4)$ & $159(90.9)$ & $103(83.7)^{\S}$ & 0.003 \\
\hline Treatment adherence evaluated $(n)$ & $327(52.7)$ & $3.4-92.6$ & $<0.001$ & 91 (50.8) & $75(52.1)$ & $98(56.0)$ & $63(51.2)$ & 0.767 \\
\hline Device satisfaction evaluated (n) & $102(16.4)$ & $0-60.5$ & $<0.001$ & $13(7.3)^{\S}$ & $31(2 \mid .5)$ & $33(18.9)$ & $25(20.3)$ & 0.001 \\
\hline Adverse effects recorded (n) & $145(23.3)$ & $4.9-66.7$ & $<0.001$ & $32(17.9)^{\S}$ & $36(25.0)$ & $52(29.7)^{\S}$ & $25(20.3)$ & 0.050 \\
\hline
\end{tabular}

Notes: *Data are expressed as mean (SD) or absolute (relative) frequencies depending on the nature of the variable. ${ }^{\#}$ Calculated for the variability between centers using ANOVA and Chi-square test, depending on the nature of the variable. ${ }^{\ddagger}$ Calculated for the variability between seasons using ANOVA and Chi-square test, depending on the nature of the variable. ${ }^{\S}$ Significant difference $(P<0.05)$ versus the rest of the seasons calculated using a Chi-square test.

Abbreviations: ANOVA, analysis of variance; mMRC, modified Medical Research Council; SD, standard deviation; CAT, COPD assessment test.

assessment test increased in winter; sputum color and hospitalizations were recorded less frequently in autumn and increased in summer. During autumn, the recording of previous exacerbations, smoking status, inhaler device satisfaction, and adverse effects decreased, whereas the recording of the current pharmacological strategy increased.

The different complementary diagnostic evaluations requested during the 4 seasons are presented in Table 3. Only the measurement of serum $\alpha 1$-antitrypsin level was found to be influenced by the seasons, with a decrease in spring. The final treatment-related recommendations after the follow-up visit during the 4 seasons are presented in Table 4 . Only the decision as to whether to discharge the patient from the clinic was influenced by the season, with an increase during the summertime.

After adjusting for covariates, only the assessment of inhaler device satisfaction was found to significantly differ according to seasons with an increase in winter (OR, 3.460; 95\% CI, 1.469-8.151), spring (OR, 4.215; 95\% CI, $1.814-$ 9.793), and summer (OR, 3.371; 95\% CI, 1.391-8.169) compared to autumn. Notably, inhaler device satisfaction was low in the majority of centers (Table 2), peaking at $60.5 \%$ in 1 center. In fact, those seasons with device satisfaction more frequently recorded reached an average maximum of $21.5 \%$.
The rest of the observed differences were not significant when adjusted for covariates (data not shown).

\section{Discussion}

The Andalusian COPD audit was the first to evaluate the quality of care in COPD treatment in specialized respiratory outpatient clinics. The present study explores the potential influence of seasons on clinical care. The results of the study showed that after controlling for confounders, there is no relationship between seasons and clinical practice.

The analysis of clinical performance against the recommended care has provided relevant information on how care is provided to COPD patients. ${ }^{16} \mathrm{Clinical}$ audits are conceived as a tool to summarize the clinical performance of health care over a specified period of time and are aimed at providing information to health care professionals to allow them to assess and adjust their performance. ${ }^{17}$ Although clinical performance has been extensively studied during COPD admissions, ${ }^{18,19}$ the situation in outpatient clinics has been mainly evaluated in the Andalusian COPD audit, ${ }^{12}$ providing information on clinicians' adherence to guidelines ${ }^{16}$ and pharmacological treatment performance. ${ }^{20}$ Previous studies have evaluated the rates of adherence to GOLD guidelines 
Table 3 Complementary diagnostic evaluations requested

\begin{tabular}{|c|c|c|c|c|c|c|c|c|}
\hline Variables & $\begin{array}{l}\text { Average* } \\
(n=621)\end{array}$ & $\begin{array}{l}\text { Interhospital } \\
\text { range }\end{array}$ & $P$-value $\#$ & $\begin{array}{l}\text { Autumn } \\
(n=179)\end{array}$ & $\begin{array}{l}\text { Winter } \\
(n=144)\end{array}$ & $\begin{array}{l}\text { Spring } \\
(n=175)\end{array}$ & $\begin{array}{l}\text { Summer } \\
(n=123)\end{array}$ & $P$-value \\
\hline Chest radiography (n) & $426(68.6)$ & $19.2-100$ & $<0.001$ & $119(66.5)$ & $103(71.5)$ & $116(66.3)$ & $88(7 \mid .5)$ & 0.418 \\
\hline Spirometry (n) & $510(82.1)$ & $52.5-100$ & $<0.001$ & I54 (86.0) & $116(80.6)$ & I43 (8I.7) & $97(78.9)$ & 0.389 \\
\hline Computed tomography (n) & $96(15.5)$ & $2.5-37.5$ & $<0.001$ & $28(15.6)$ & $20(13.9)$ & 31 (17.7) & $17(13.8)$ & 0.751 \\
\hline Echocardiogram (n) & $36(5.8)$ & $0-9.9$ & 0.325 & $10(5.6)$ & $6(4.2)$ & $10(5.7)$ & $10(8.1)$ & 0.584 \\
\hline Sputum eosinophilia (n) & $0(0)$ & $0-0$ & - & $0(0)$ & $0(0)$ & $0(0)$ & $0(0)$ & - \\
\hline Serum total lgE (n) & $34(5.5)$ & $0-17.2$ & $<0.001$ & $13(7.3)$ & $8(5.6)$ & $6(3.4)$ & $7(5.7)$ & 0.469 \\
\hline Serum $\alpha$ I-antitripsin (n) & $53(8.5)$ & $0-19.8$ & $<0.001$ & $20(11.2)$ & $18(12.5)$ & $8(4.6)^{\S}$ & $7(5.7)$ & 0.026 \\
\hline Sputum culture (n) & $53(8.5)$ & $0-23.4$ & $<0.001$ & $16(8.9)$ & $13(9.0)$ & $16(9.1)$ & $8(6.5)$ & 0.846 \\
\hline Six-minute walking test $(n)$ & $110(17.7)$ & $0-82.5$ & $<0.001$ & $33(18.4)$ & $27(18.8)$ & $26(14.9)$ & $24(19.5)$ & 0.700 \\
\hline Shuttle walking test $(n)$ & $0(0)$ & $0-0$ & - & $0(0)$ & $0(0)$ & $0(0)$ & $0(0)$ & - \\
\hline Cardiopulmonary exercise test (n) & $3(0.5)$ & $0-3.4$ & 0.316 & $2(1.1)$ & $0(0)$ & $0(0)$ & $\mathrm{I}(0.8)$ & 0.344 \\
\hline Densitometry (n) & $4(0.6)$ & $0-5.1$ & 0.001 & $2(1.1)$ & $0(0)$ & $0(0)$ & $\mathrm{I}(0.8)$ & 0.653 \\
\hline $\begin{array}{l}\text { Any other health status } \\
\text { questionnaires excluding CAT (n) }\end{array}$ & $0(0)$ & $0-0$ & - & $0(0)$ & $0(0)$ & $0(0)$ & $0(0)$ & - \\
\hline
\end{tabular}

Notes: *Data are expressed as mean (SD) or absolute (relative) frequencies depending on the nature of the variable. \#Calculated for the variability between centers using ANOVA and Chi-square test, depending on the nature of the variable. ${ }^{\ddagger}$ Calculated for the variability between seasons using ANOVA and Chi-square test, depending on the nature of the variable. ${ }^{\circledR}$ Significant difference versus the rest of the seasons.

Abbreviations: ANOVA, analysis of variance; SD, standard deviation; CAT, COPD assessment test.

for COPD treatment among pulmonologists; however, these studies focus exclusively on pharmacological treatments. ${ }^{21-23}$ In the present study, we evaluated a typical follow-up clinical visit, and thus, in turn, determined the degree to which the doctor in-charge follows and records the recommended information, highlighting the variability of performance throughout the different seasons.

In order to interpret our results correctly, some considerations need to be made. 1) The Andalusian COPD audit was conceived as a pilot study. This implies that there was no randomization of centers, and that the variables included were not all possible. Accordingly, randomization of a center in wider geographical areas and a comprehensive evaluation of different variables and clinical outcomes would improve the representativeness of the sample. After this first experience, we identify the need to confirm our findings in a nationally representative audit, expanding the area studied and increasing the number of variables. 2) It is important to evaluate the effect of guideline adherence on clinically relevant outcomes. Accordingly, a follow-up of patients

Table 4 Final treatment-related decisions recommended after the follow-up visit

\begin{tabular}{|c|c|c|c|c|c|c|c|c|}
\hline Variables & $\begin{array}{l}\text { Average* } \\
(n=62 I)\end{array}$ & $\begin{array}{l}\text { Interhospital } \\
\text { range }\end{array}$ & $P$-value ${ }^{\#}$ & $\begin{array}{l}\text { Autumn } \\
(n=\mid 79)\end{array}$ & $\begin{array}{l}\text { Winter } \\
(n=\mid 44)\end{array}$ & $\begin{array}{l}\text { Spring } \\
(n=175)\end{array}$ & $\begin{array}{l}\text { Summer } \\
(n=123)\end{array}$ & $P_{\text {-value }}^{\ddagger}$ \\
\hline Diagnosis of COPD recorded $(n)$ & $603(97.1)$ & $94.5-100$ & $<0.001$ & $172(96.1)$ & 140 (97.2) & $170(97.1)$ & I2I (98.4) & 0.713 \\
\hline GOLD type identified (n) & $224(36.1)$ & $3.4-100$ & $<0.001$ & $61(34.1)$ & $52(36.1)$ & $70(40.0)$ & $4 \mathrm{I}(33.3)$ & 0.598 \\
\hline GesEPOC phenotype identified (n) & $294(47.3)$ & $8.6-95.0$ & $<0.001$ & $76(42.5)$ & $68(47.2)$ & $94(53.7)$ & $56(45.5)$ & 0.193 \\
\hline GOLD or GesEPOC patient type identified (n) & $423(68.1)$ & $13.8-100$ & $<0.001$ & II 5 (64.2) & $100(69.4)$ & $129(73.7)$ & $79(64.2)$ & 0.192 \\
\hline Detailed treatment recommendations (n) & $603(97.1)$ & $89.7-100$ & $<0.001$ & $173(96.6)$ & |4| (97.9) & I7| (97.7) & I I 8 (95.9) & 0.729 \\
\hline Recommendation on smoking (n) & $278(44.8)$ & $8.6-92.6$ & $<0.001$ & $82(45.8)$ & $58(40.3)$ & $84(48.0)$ & $54(43.9)$ & 0.566 \\
\hline Recommendation on exercise $(\mathrm{n})$ & $276(44.4)$ & $2.5-88.9$ & $<0.001$ & 7I (39.7) & $72(50.0)$ & $81(46.3)$ & $52(42.3)$ & 0.269 \\
\hline Recommendation on influenza vaccine $(n)$ & $269(43.3)$ & $2.5-93.8$ & $<0.001$ & $73(40.8)$ & $52(36.1)$ & $86(49.1)$ & $58(47.2)$ & 0.083 \\
\hline Recommendation on pneumococcal vaccine $(n)$ & $116(18.7)$ & $0-40.7$ & $<0.001$ & $32(17.9)$ & $24(16.7)$ & $34(19.4)$ & $26(2 I . I)$ & 0.798 \\
\hline Pharmacological treatment changed (n) & $199(35.2)$ & $10.5-58.0$ & $<0.001$ & $54(32.0)$ & $49(36.0)$ & $57(36.1)$ & $39(38.2)$ & 0.732 \\
\hline \multicolumn{9}{|l|}{ Type of pharmacological change } \\
\hline Increase in the number of drugs (n) & $99(17.5)$ & $5.6-28.4$ & 0.023 & $26(15.4)$ & $26(19.1)$ & $28(17.7)$ & $19(18.6)$ & 0.834 \\
\hline Decrease in the number of drugs $(n)$ & $55(9.7)$ & $0-14.5$ & 0.286 & $18(10.7)$ & $12(8.8)$ & $14(8.96)$ & II (I0.8) & 0.907 \\
\hline Change in drug type (n) & $45(8.0)$ & $0-19.8$ & 0.003 & $10(5.9)$ & II (8.I) & I5 (9.5) & $9(8.8)$ & 0.665 \\
\hline Discharged from the clinic (n) & $30(4.8)$ & $0-16.5$ & $<0.001$ & $6(3.4)$ & $5(3.5)$ & $6(3.4)$ & $13(10.6)^{\S}$ & 0.012 \\
\hline
\end{tabular}

Notes: *Data are expressed as mean (SD) or absolute (relative) frequencies depending on the nature of the variable. ${ }^{\#}$ Calculated for the variability between centers using ANOVA and Chi-square test, depending on the nature of the variable. ${ }^{\ddagger}$ Calculated for the variability between seasons using ANOVA and Chi-square test, depending on the

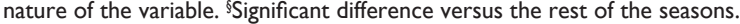

Abbreviations: ANOVA, analysis of variance; COPD, chronic obstructive pulmonary disease; SD, standard deviation. 
is needed to evaluate the effect of guideline adherence on exacerbation rates and survival. 3) There are potential intrinsic limitations resulting from different auditors evaluating different medical records. To avoid this, we analyzed the database looking for missing, extreme, or inconsistent values, and such values were returned to the investigators for correction. 4) Finally, although global climate change has already had observable effects on the environment, resulting in a significant increase in the morbidity and mortality of patients with chronic lung disease ${ }^{24}$ and increased prevalence of certain respiratory diseases, ${ }^{25}$ due to the slow progression of climate change and global warming, 1 year is probably insufficient to evaluate the effect of climate change on clinical practice. Therefore, the present study does not aim to evaluate the effect of global warming on clinical practice but only studies possible variations in COPD care in a year. Notwithstanding the foregoing, geographical and time variations could influence our results. Significant year-to-year variations in climate conditions within a particular geographical area might affect our results. In addition, climate differences among the different areas in the country might also have an effect. Although Andalusia has extreme temperatures ranging from very high temperatures and high pressures during the summer to considerably cold winter months with temperatures reaching $<0^{\circ}$, other parts of Spain may get colder during the year. Therefore, the results might have been different if the study would have been carried out in a region with more extreme climate changes throughout the year. We are currently analyzing the results of a nationwide clinical audit that will allow us to analyze seasonal variation in the country.

The results of the present analysis indicate that clinicians do not alter their clinical practice according to the seasons. A recent body of evidence has shown the variation in symptom perception by patients during the 24 hours of a day. ${ }^{26,27}$ However, although there is information on the distribution of exacerbation during the seasons, ${ }^{28}$ very little information is available regarding the variability of symptoms during a year. Although 1 study has focused on the effect of seasons on physical activity, ${ }^{29}$ the majority of the evidence shows that exacerbations increase during the cold months. ${ }^{30}$ However, in a stable state, there is little evidence of an association between the seasons and the symptoms perceived by patients. Should this association exist, it would result in an expected change in clinical performance across seasons. However, the differences found here are explained by the severity of the disease, indicating that this is the main driver of clinical decisions rather than the seasons. A recent analysis of the same database indicated that exacerbations and symptoms were the main factors for stepping up treatment, and $\mathrm{FEV}_{1}$ and previous treatment with long-term antibiotics or inhaled steroids were the key determinants for stepping down treatment. ${ }^{20}$ Thus, our data suggest that clinicians adapt their performance in accordance with clinical manifestations rather than the time of the year.

The association of inhaler device satisfaction with respect to the seasons has not been described previously. Nonetheless, we need to be cautious with this relationship. Because of the pilot nature of the study, the number of variables was limited. Accordingly, a detailed evaluation of inhaler satisfaction was not included in the audit, and investigators were only asked to check whether the degree of satisfaction with the inhalation device was recorded during the clinical visit. Clearly, adherence evaluation and inhaler device satisfaction are crucial for a chronic respiratory condition. Many studies have highlighted the importance of treatment adherence and a correct inhaler technique in COPD. ${ }^{31}$ Patients' satisfaction with the inhaler has been associated with compliance and health status in COPD, ${ }^{32}$ where the role of the doctor in-charge is also crucial. ${ }^{33}$ It follows that patient satisfaction with the inhaler should be routinely evaluated. Recently, patient preference and acceptability of inhaler devices have been evaluated using the Handling Questionnaire, ${ }^{19}$ a validated questionnaire specifically designed to identify and compare the features for choice and acceptability of different inhalation devices in patients with persistent airway obstruction. ${ }^{34}$

\section{Conclusion}

In summary, the analysis of the Andalusian COPD audit data on seasonal variability of clinical practice indicates a lack of association between seasons and clinical COPD care, after controlling for confounders, except for recording inhaler device satisfaction, which decreased in autumn in our region, but with a low compliance of this clinically relevant evaluation. The present data should encourage clinicians to increase awareness of the importance of evaluating inhaler satisfaction to improve clinical care for COPD patients.

\section{Acknowledgments}

The authors thank Juan Manuel Praena from the Statistics Department at Virgen del Rocío University Hospital for providing statistical support in the present analysis. This study was funded by an unrestricted grant from Menarini, Spain. 


\section{Disclosure}

The authors report no conflicts of interest in this work.

\section{References}

1. López-Campos JL, Tan W, Soriano JB. Global burden of COPD. Respirology. 2016;21(1):14-23.

2. Marin JM, Cote C, Casanova C, et al; En Representación del Grupo BODE. Simplifying the guidelines: the 10 COPD commandments Arch Bronconeumol. 2016;52(4):179-180.

3. Munn Z, Scarborough A, Pearce S, et al. The implementation of best practice in medication administration across a health network: a multisite evidence-based audit and feedback project. JBI Database System Rev Implement Rep. 2015;13(8):338-352.

4. Pozo-Rodriguez F, Castro-Acosta A, Alvarez CJ, et al. Determinants of between-hospital variations in outcomes for patients admitted with COPD exacerbations: findings from a nationwide clinical audit (AUDIPOC) in Spain. Int J Clin Prac. 2015;69(9):938-947.

5. Gasparrini A, Guo Y, Hashizume M, et al. Mortality risk attributable to high and low ambient temperature: a multicountry observational study. Lancet. 2015;386(9991):369-375.

6. Lam HC, Li AM, Chan EY, Goggins WB 3rd. The short-term association between asthma hospitalisations, ambient temperature, other meteorological factors and air pollutants in Hong Kong: a time-series study. Thorax. Epub 2016 Jun 24.

7. Psoter KJ, DE Ross AJ, Wakefield J, Mayer JD, Bryan M, Rosenfeld M. Association of meteorological and geographical factors and risk of initial Pseudomonas aeruginosa acquisition in young children with cystic fibrosis. Epidemiol Infect. 2016;144(5):1075-1083.

8. Huang F, Zhao A, Chen RJ, Kan HD, Kuang XY. Ambient temperature and outpatient visits for acute exacerbation of chronic bronchitis in Shanghai: a time series analysis. Biomed Environ Sci. 2015;28(1):76-79.

9. Lopez-Campos JL, Asensio-Cruz MI, Castro-Acosta A, Calero C, Pozo-Rodriguez F; AUDIPOC and the European COPD Audit studies. Results from an audit feedback strategy for chronic obstructive pulmonary disease in-hospital care: a joint analysis from the AUDIPOC and European COPD audit studies. PLoS One. 2014;9(10):e110394.

10. Liesker JJ, Bathoorn E, Postma DS, Vonk JM, Timens W, Kerstjens HA. Sputum inflammation predicts exacerbations after cessation of inhaled corticosteroids in COPD. Respir Med. 2011;105(12):1853-1860.

11. Seemungal T, Harper-Owen R, Bhowmik A, et al. Respiratory viruses, symptoms, and inflammatory markers in acute exacerbations and stable chronic obstructive pulmonary disease. Am J Respir Crit Care Med. 2001; 164(9):1618-1623.

12. López-Campos JL, Abad Arranz M, Calero Acuña C, et al. Clinical audits in outpatient clinics for chronic obstructive pulmonary disease: methodological considerations and workflow. PLoS One. 2015;10(11): e0141856.

13. Vestbo J, Hurd SS, Agustí AG, et al. Global strategy for the diagnosis, management, and prevention of chronic obstructive pulmonary disease: GOLD executive summary. Am J Respir Crit Care Med. 2013;187(4):347-365.

14. Miravitlles M, Soler-Cataluña JJ, Calle M, et al. Spanish guideline for COPD (GesEPOC). Update 2014. Arch Bronconeumol. 2014;50(Suppl)1:1-16.

15. Soler-Cataluña JJ, Calle M, Cosío BG, Marín JM, Monsó E, Alfageme I; Comité de Calidad Asistencial de la SEPAR; Area de Trabajo EPOC de la SEPAR. [Health-care quality standards in chronic obstructive pulmonary disease]. Arch Bronconeumol. 2009;45(4):196-203. Spanish [with English abstract].

16. López-Campos JL, Abad Arranz M, Calero-Acuña C, et al. Guideline adherence in outpatient clinics for chronic obstructive pulmonary disease: results from a clinical audit. PLoS One. 2016;11(3):e0151896.
17. Flottorp SA, Jamtvedt G, Gibis B, McKee M. Policy Summary 3. Using Audit and Feedback to Health Professionals to Improve the Quality and Safety of Health Care. Copenhagen: WHO; 2010.

18. Pozo-Rodríguez F, López-Campos JL, Alvarez-Martinez CJ, et al; AUDIPOC Study Group. Clinical audit of COPD patients requiring hospital admissions in Spain: AUDIPOC study. PLoS One. 2012;7(7): e42156.

19. Hartl S, Lopez-Campos JL, Pozo-Rodriguez F, et al. Risk of death and readmission of hospital-admitted COPD exacerbations: European COPD audit. Eur Respir J. 2016;47(1):113-121.

20. López-Campos JL, Abad Arranz M, Calero Acuña C, et al. Determinants for changing the treatment of COPD: a regression analysis from a clinical audit. Int J Chron Obstruct Pulmon Dis. 2016;11:1171-1178.

21. Asche CV, Leader S, Plauschinat C, et al. Adherence to current guidelines for chronic obstructive pulmonary disease (COPD) among patients treated with combination of long-acting bronchodilators or inhaled corticosteroids. Int J Chron Obstruct Pulmon Dis. 2012;7:201-209.

22. Price D, West D, Brusselle G, et al. Management of COPD in the UK primary-care setting: an analysis of real-life prescribing patterns. Int $J$ Chron Obstruct Pulmon Dis. 2014;9:889-904.

23. Ford ES, Mannino DM, Wheaton AG, et al. Trends in the use, sociodemographic correlates, and undertreatment of prescription medications for chronic obstructive pulmonary disease among adults with chronic obstructive pulmonary disease in the United States from 1999 to 2010. PLoS One. 2014;9(4):e95305.

24. Witt C, Schubert AJ, Jehn M, et al. The effects of climate change on patients with chronic lung disease. A systematic literature review. Dtsch Arztebl Int. 2015;112(51-52):878-883.

25. Gerardi DA, Kellerman RA. Climate change and respiratory health. J Occup Environ Med. 2014;56(Suppl 10):S49-S54.

26. Soler-Cataluña JJ, Sauleda J, Valdés L, et al. [Prevalence and perception of 24-hour symptom patterns in patients with stable chronic obstructive pulmonary disease in Spain]. Arch Bronconeumol. 2016;52(6):308-315. Spanish [with English abstract].

27. Miravitlles M, Worth H, Soler Cataluña JJ, et al. Observational study to characterise 24-hour COPD symptoms and their relationship with patient-reported outcomes: results from the ASSESS study. Respir Res. 2014;15:122.

28. Donaldson GC, Goldring JJ, Wedzicha JA. Influence of season on exacerbation characteristics in patients with COPD. Chest. 2012;141(1): 94-100.

29. Alahmari AD, Mackay AJ, Patel AR, et al. Influence of weather and atmospheric pollution on physical activity in patients with COPD. Respir Res. 2015;16:71.

30. Almagro P, Hernandez C, Martinez-Cambor P, Tresserras R, Escarrabill J. Seasonality, ambient temperatures and hospitalizations for acute exacerbation of COPD: a population-based study in a metropolitan area. Int J Chron Obstruct Pulmon Dis. 2015;10:899-908.

31. Sriram KB, Percival M. Suboptimal inhaler medication adherence and incorrect technique are common among chronic obstructive pulmonary disease patients. Chron Respir Dis. 2016;13(1):13-22.

32. Chrystyn H, Small M, Milligan G, Higgins V, Gil EG, Estruch J. Impact of patients' satisfaction with their inhalers on treatment compliance and health status in COPD. Respir Med. 2014;108(2):358-365.

33. Cecere LM, Slatore CG, Uman JE, et al. Adherence to long-acting inhaled therapies among patients with chronic obstructive pulmonary disease (COPD). COPD. 2012;9(3):251-258.

34. Dal Negro RW, Guerriero M. Cultural and linguistic testing of the handling questionnaire: a specific instrument for assessing the patient's acceptability of dry powder inhalers. Monaldi Arch Chest Dis. 2008; 69(4):170-177. 
International Journal of COPD

Dovepress

\section{Publish your work in this journal}

The International Journal of COPD is an international, peer-reviewed journal of therapeutics and pharmacology focusing on concise rapid reporting of clinical studies and reviews in COPD. Special focus is given to the pathophysiological processes underlying the disease, intervention programs, patient focused education, and self management protocols.

This journal is indexed on PubMed Central, MedLine and CAS. The manuscript management system is completely online and includes a very quick and fair peer-review system, which is all easy to use. Visit http://www.dovepress.com/testimonials.php to read real quotes from published authors.

Submit your manuscript here: http://www.dovepress.com/international-journal-of-chronic-obstructive-pulmonary-disease-journal 